\title{
RUPTURE COMPLEXITY OF THE 1970 TONGHAI AND 1973 LUHUO EARTHQUAKES, CHINA, FROM $P$-WAVE INVERSION, AND RELATIONSHIP TO SURFACE FAULTING
}

\author{
By Hui-lan Zhou,* Clarence R. Allen, and Hiroo Kanamori
}

\begin{abstract}
The source processes of the 4 January 1970 , Tonghai earthquake $\left(M_{s}=7.5\right)$ and the 6 February 1973 , Luhuo earthquake $\left(M_{S}=7.5\right)$ in southwestern China were investigated using an inversion technique on the very complex body waves. The two earthquakes were associated with 48 and $90 \mathrm{~km}$ of surficial strike-slip rupture, respectively, and the distribution of displacement with distance along the fault was well documented by field studies of both events. The source process for both earthquakes comprised three to four subevents with different moments and rupture durations. These calculated parameters agree well with the field observations and aftershock distributions, particularly in the total rupture length and in the amount and asymmetry of fault displacements relative to the locations of the main epicenters.
\end{abstract}

\section{INTRODUCTION}

The purpose of this study was to understand better the detailed sequence of events during fault rupture associated with large earthquakes. Two Chinese earthquakes have been chosen because each was associated with surficial fault displacements that were unusually well documented by field studies, and because each gave rise to complex $P$ waveforms that were well recorded on WWSSN stations. The 4 January 1970, Tonghai earthquake $\left[M_{S}=7.7\right.$ (China), 7.5 (USGS)] occurred in Yunnan Province on the Qujiang fault, which is parallel to and possibly a branch of the much longer right-lateral Honghe (Red River) fault system. The 6 February 1973, Luhuo earthquake $\left[M_{S}=7.9\right.$ (China), 7.5 (USGS) $]$ occurred in Sichuan Province on the left-lateral Xianshuihe fault (Figure 1a). Both the Honghe and Xianshuihe faults are major throughgoing tectonic features of southwestern China (Molnar and Tapponnier, 1975; Kan et al., 1977; Allen et al., 1982). The $P$ waveforms of these two large strike-slip events recorded at WWSSN stations are very complex and difficult to explain by a single point-source or a single propagating-source model. Kanamori and Stewart (1978) explained the complexity of $P$ waves radiated by the 4 February 1976, Guatemala, earthquake from the viewpoint of asperities or barriers on the fault plane that controlled the sequence of individual subevents during the rupture process. Recently, Kikuchi and Kanamori (1982) developed a technique using complex body waves to study the source processes in greater detail. In the present study, we use Kikuchi and Kanamori's technique to investigate the source processes of these two large Chinese earthquakes and to understand the character of the faulting, and we attempt to compare the results with the distribution of surficial fault offsets observed in the field following these two events.

\section{Field OBSERvations}

Geological field studies following the Tonghai and Luhuo earthquakes revealed that the surficial fault rupture in both cases was dominantly strike slip and relatively

* Present address: Department of Earth and Space Sciences, Unıversity of Science and Technology, Hefer, Anhui, People's Republic of China. 
simple. The distribution of displacements as a function of distance along the fault was unusually well documented for both earthquakes (Figures 2 and 3), which is one reason they were chosen for study.

The length of surface rupture for the 1970 Tonghai earthquake was about $48 \mathrm{~km}$, which is somewhat less than is typical for events of this magnitude (Slemmons,

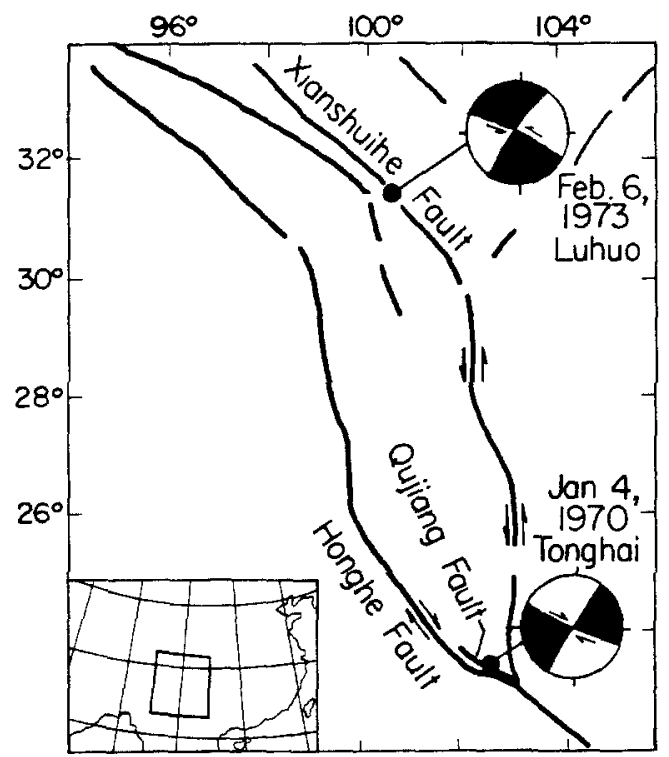

a
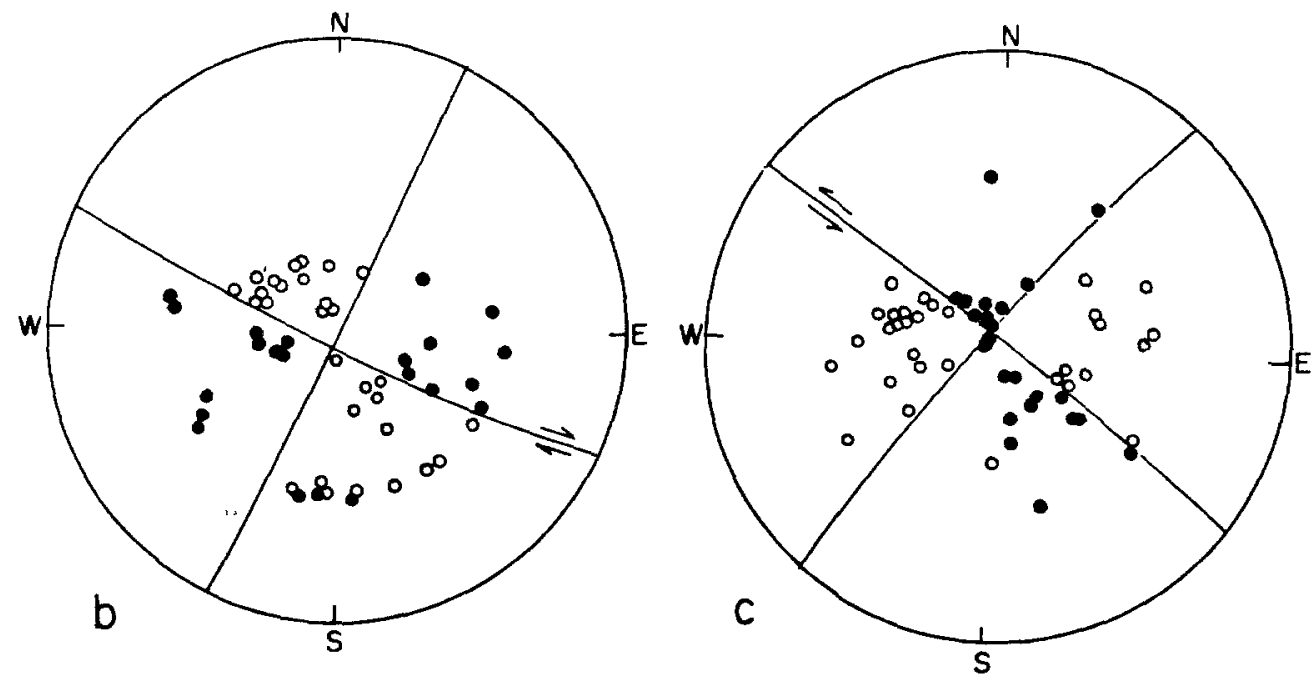

Fig. 1 (a) Locations of the 1970 Tonghal and 1973 Luhuo earthquakes in southwestern China, showing major regional faults and summary focal mechanisms. (b) Focal mechanism for the Tonghai earthquake. Fault strike, $\phi=116^{\circ}$; $\operatorname{dip}, \delta=86^{\circ}$; slip angle, $\lambda=0^{\circ}$ (c) Focal mechanısm for the Luhuo earthquake $\phi=125^{\circ}, \delta=87^{\circ}$, and $\lambda=0^{\circ}$. The first-motion data on the lower focal hemisphere are shown (open circle, dilatation; closed circle, compression).

1977), although the total length of the aftershock zone was about $90 \mathrm{~km}$ and probably more closely represents the extent of faulting at depth. Zhang and Liu (1978) indicate that the maximum strike-slip displacement of about $2.7 \mathrm{~m}$ occurred near the northwestern end of the fault trace, not far from the approximate epicenter 


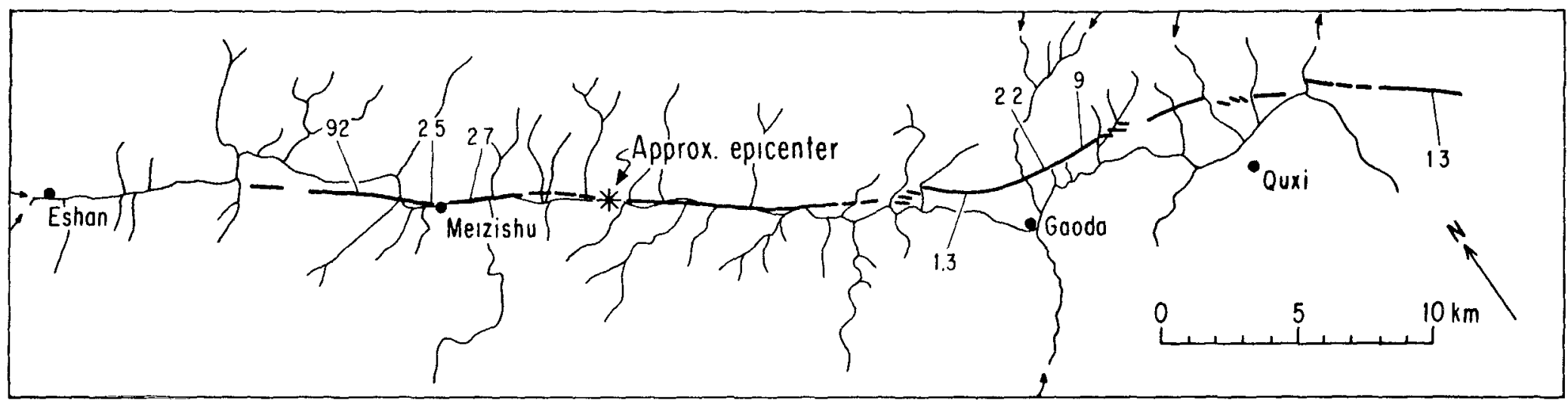

FIG 2 Map of surficial fault rupture (heavy line) associated with 1970 Tonghal earthquake, from Zhang and Liu (1978). Figures indicate observed right-lateral displacement, in meters. Dramage pattern, added from Landsat imagery, is approxımate only.

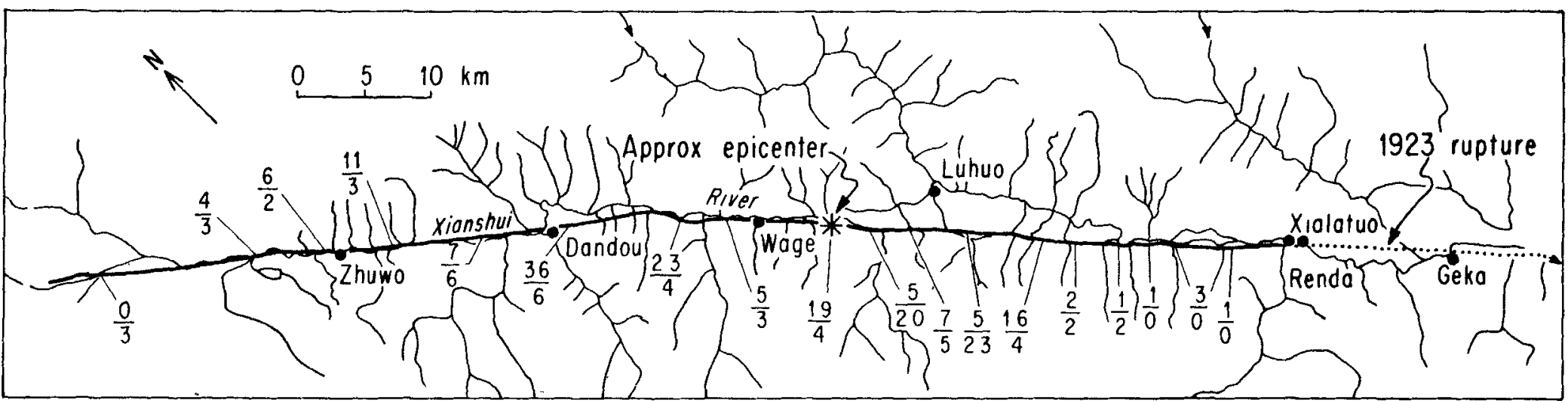

Fic 3. Map of surficial fault rupture (heavy line) associated with 1973 Luhuo earthquake, from Tang et al (1976). Figures indicate observed left-lateral displacement (above bar) and vertical displacement (below bar), in meters. Dotted line (right) shows trace of 1923 rupture, from Heim (1934) Note that scales of Figures 2 and 3 are difterent. 
(Figure 2), although this point is near midway within the total aftershock zone. Figure 2 shows that the fault trace consisted of several discrete segments connected by zones of distributed en-echelon breaks, and the displacement-versus-distance relationship was relatively smooth. This has been an area of relatively high continuing seismic activity throughout recorded history, although no earlier surficial displacements along the Qujiang fault have been documented. Field visits by one of the authors (C. R. A.) have verified that the fault has a history of late Quaternary movements, as indicated, for example, by right-lateral stream offsets north of Gaoda and rift topography and closed depressions west of Meizishu. Study of Landsat imagery suggests that the total extent of the Qujiang fault is not significantly longer than the segment which broke in 1970, as indicated by the extent of aftershocks; near the eastern extremity of the 1970 aftershock activity, the Qujiang fault is abruptly truncated by north-trending members of the Xiaojiang fault system, although the fault does appear to continue some distance northwest beyond the western termination of aftershock activity.

The 1973 Luhuo earthquake was associated with about $90 \mathrm{~km}$ of surface rupture along the Xianshuihe fault (Figure 3), which was exceptionally well described by Tang et al. (1976). The fault trace was remarkably linear and continuous, with the epicenter located about midway along its length. Aftershocks are not as well located as for the Tonghai earthquake, but they appear to cover a wide area, particularly north and west of the rupture zone; some of these have been discussed in detail by Zhou et al. (1982). The Xianshuihe fault has a much greater total extent than that broken in 1973 (Figure 1a), and various parts of the fault have been the locus of many large historical earthquakes; indeed, it has been among the most highly seismic areas in China during this century. Most recently, the 1981 Daofu earthquake $\left(M_{S}=6.8\right)$ was associated with $44 \mathrm{~km}$ of surface rupture along the Xianshuihe fault in the area southeast of that shown in Figure 3. The 1923 Daofu earthquake $\left(M_{S}=7 \frac{1}{4}\right)$ seems to have been centered in the intervening area (Heim, 1934), with some overlap with both the 1973 and 1981 events. Tang et al. (1976) point out that some of the same fractures that broke in 1923 near Renda and Xialatuo "Sharato" of Heim, 1934) were rebroken in 1973 (Figure 3). This emphasizes the high degree of current activity of this part of the Xianshuihe fault zone. Field descriptions by Tang et al. (1976) and Heim (1934), as well as examination of Landsat imagery, leave little doubt that the Xianshuihe fault in this region has had a history of abundant late Quaternary movements.

\section{Data Analysis AND Results}

All the seismograms used in this study are from WWSSN stations. We use only those records that provide a $P$-wave train with a duration of at least $1.8 \mathrm{~min}$ without interference from the $P P$ phase. The $P$ waveforms of both the Tonghai and Luhuo earthquakes (as shown in Figures 6 and 10) are very complex, suggesting a complicated rupture process. In order to interpret these complex waveforms in terms of the source rupture process, we use the inversion method described by Kikuchi and Kanamori (1982).

Since the fault geometry of these events is known from the $P$-wave first-motion data and field observations, we fix it in our inversion. In the method of Kikuchi and Kanamori (1982), a linear ramp function with a rise time is used to invert the waveform. Following Kikuchi and Kanamori, we choose the rise time such that the synthetic waveform can match the first half-period of the observed $P$ waveform.

As a preliminary test, we first invert the data from the individual stations and 
examine whether the source-time functions obtained from the individual stations are similar to each other (single-station method). Next, we invert the data from all the stations simultaneously to obtain the source-time function, taking the azimuthdependent time shift into account (multi-station method). In the inversion of the multi-station data, we place 11 point sources along the fault, with a spatial separation, $\Delta l$, of $15 \mathrm{~km}$. The number of iteration, $N$, is fixed at 15 . Increasing $N$ beyond 15 decreases the error only by an insignificant amount (Figure 4c). At the final stage of the inversion, we slightly modify $N$, the geometric parameters, and the total rupture length to check the stability of the solution. In what follows, we describe further details for each event.

\section{Tonghai}

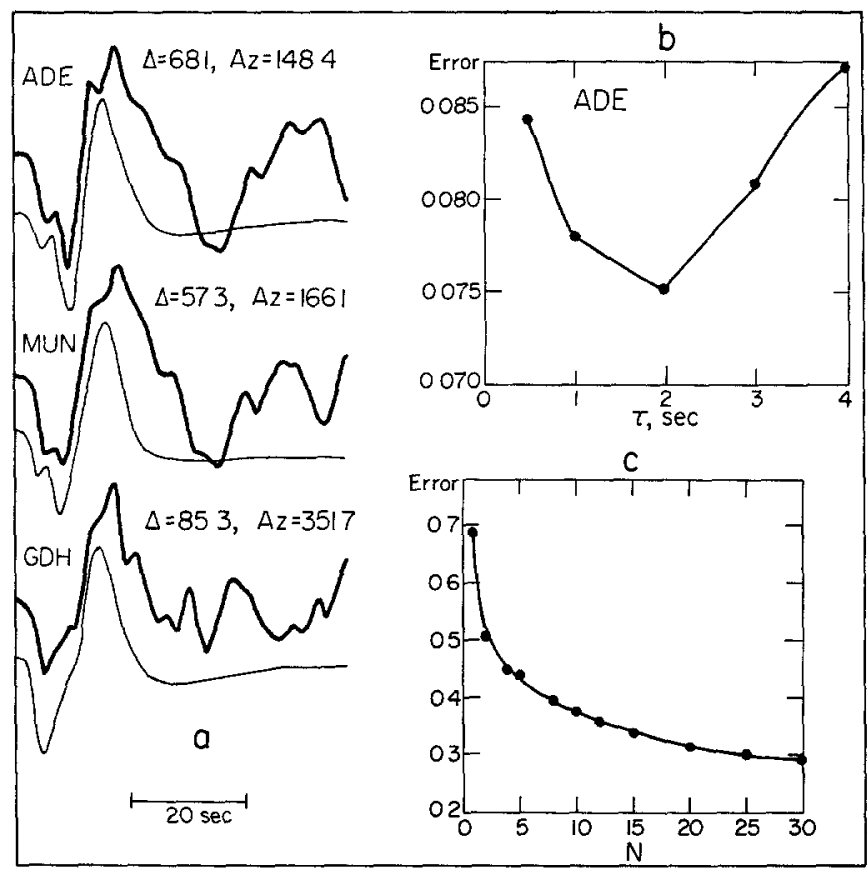

FIG. 4. Tonghar earthquake (a) Comparison of observed waves (heavy line) with synthetic waves (light line) for the first half-period, using a rise time of 2 sec. (b) Error in inversion results for station ADE versus rise time. (c) Normalized approximation error versus number of iterations (for multi-station data), for $\tau=2 \sec$ and $\Delta l=15 \mathrm{~km}$.

Tonghai earthquake. Figure $1 \mathrm{~b}$ shows the focal mechanism of the Tonghai event determined from the $P$-wave first-motion data from local Chinese as well as WWSSN stations. The northwest-striking nodal plane, with strike, $\phi=116^{\circ}$, and $\operatorname{dip}, \delta=86^{\circ}$ (the slip angle on this plane, $\lambda=0^{\circ}$ ), is considered to be the fault plane, because its strike coincides closely with that of the surface rupture associated with the earthquake.

Figure $4 \mathrm{a}$ shows that, if the rise time $\tau=2 \mathrm{sec}$ of the unit ramp source function is chosen, the synthetic waveforms of the first half-period match the observed waveforms reasonably well. The point source is placed at the depth of $9 \mathrm{~km}$. Although a finite source distributed over a depth range is more appropriate to represent an event with this magnitude, this depth is chosen to match the complex interference pattern during the few seconds of the waveform. In fact, a minimum 
of the error occurs at $\tau=2 \mathrm{sec}$ for the fixed number of iterations $(N=15)$ (Figure $4 b$ ).

By using the multi-station data with $\Delta l=15 \mathrm{~km}$ and $N=15$, we obtain the source-time function shown in Figure 5a. Since the solution depends on $\Delta l$ and $N$ to some extent, we try the inversion for different combinations of $\Delta l$ and $N$ as shown in Table 1, and the results are shown in Figure 5, b to d. We identify

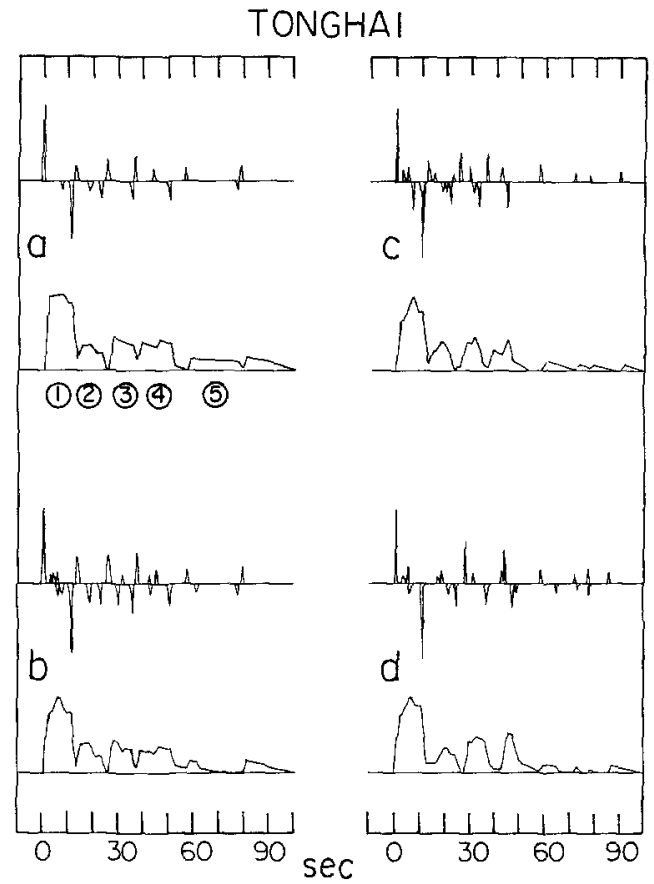

FIG. 5 Stability of source-time function for Tonghaı earthquake obtained by multi-station deconvolution The source time functions (a) to (d) are obtained for the four cases given in Table 1. Subevents (1), (2), and (3) appear stable, but after $40 \mathrm{sec}$ the time function is not well constrained.

TABLE 1

The Effect of Changing $3 l$ AND $N$ On The ERroR*

\begin{tabular}{ccccc}
\hline Case & $\begin{array}{c}\Delta l \\
(\mathrm{~km})\end{array}$ & $N$ & $\begin{array}{c}e \\
\text { (relative) }\end{array}$ & $\begin{array}{c}M_{0} \\
\left(10^{26} \mathrm{dyne}-\mathrm{cm}\right)\end{array}$ \\
\hline $\mathrm{a}$ & 15 & 15 & 0.34 & 11 \\
$\mathrm{~b}$ & 15 & 15 & 0.29 & 9.6 \\
$\mathrm{c}$ & 10 & 15 & 035 & 8.4 \\
$\mathrm{~d}$ & 20 & 30 & 0.28 & 8.4 \\
\hline
\end{tabular}

* The mechanism ( $\left.\operatorname{strkke} \varphi=116^{\circ}, \operatorname{dip} \delta=86^{\circ}, \operatorname{sl} p \lambda=0\right), \operatorname{depth}(h$ $=9 \mathrm{~km})$, and rise time $(\tau=2 \mathrm{sec})$ are fixed. The number of stations used is 7

subevents 1, 2, 3, 4, and 5 as marked in Figure 5a. Since the main features during the first $40 \mathrm{sec}$ are essentially the same for the different combinations of $\Delta l$ and $N$, we conclude that subevents 1,2 , and 3 represent the real source complexity. Since the shape of subevents 4 and 5 varies substantially for the different cases, their significance is questionable. As Figure 6 shows, the synthetic waveforms match very well those observed during the first $30 \mathrm{sec}$, but the fit deteriorates after $40 \mathrm{sec}$.

Figure 7 shows the space-time distribution of the pulses shown in Figure 6 . 
Although we believe that the overall temporal complexity for the first $30 \mathrm{sec}$ shown in Figure 6 is a required feature, the spatial distribution of the pulses shown in Figure 7 is subject to large uncertainties because of the difficulty in accurately determining the onset of the pulses, especially for the later events. We tried

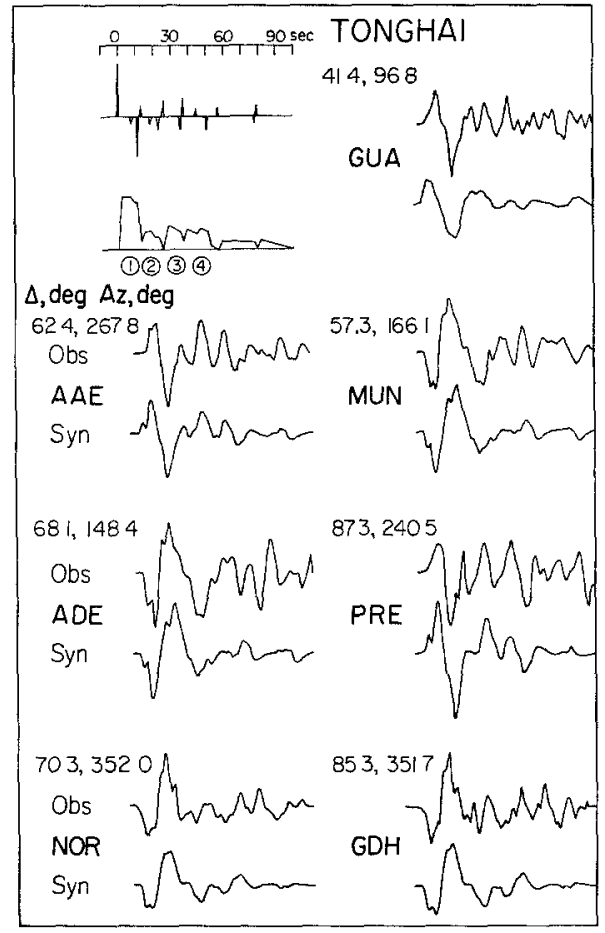

FIG 6. Observed and synthetıc $P$ waveforms for Tonghai earthquake, based on source-time function of Figure 5a.

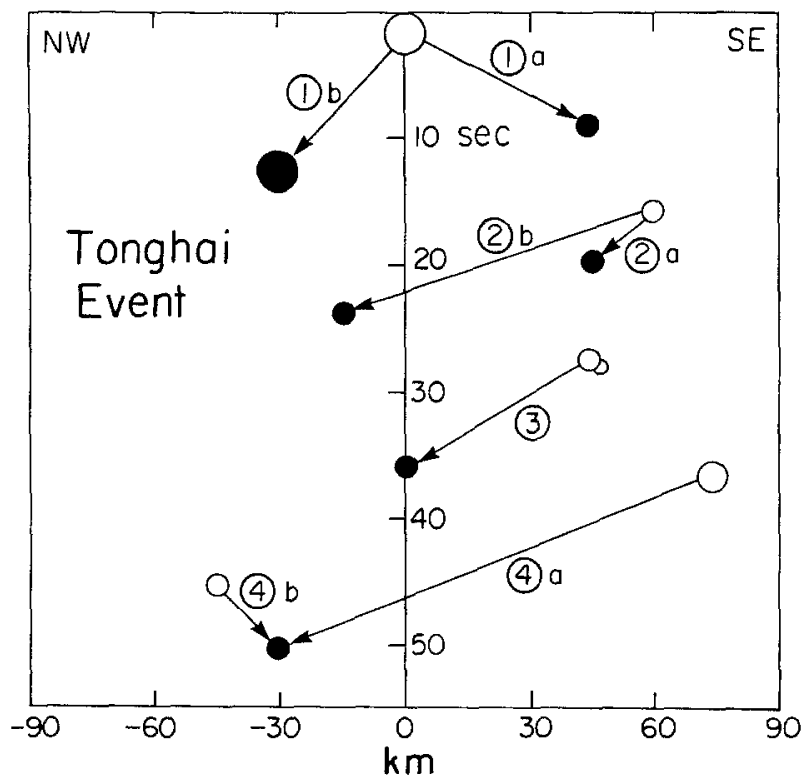

Fig 7 Time-space distribution of pulses shown in Figure 5a for Tonghaı earthquake Open circles are positive pulses, solid circles are negatıve pulses. Sizes of circles correspond to heights of individual ramp functions. 
inversions while changing $\Delta l$ from 0 (i.e., with the source forced to be a point source) to $30 \mathrm{~km}$. Although a reasonably good fit between the synthetic and observed waveforms and a similar time function are obtained in all cases, the error is reduced significantly when $\Delta l$ is larger than $5 \mathrm{~km}$ (Figure 8), indicating that the fault length is at least $50 \mathrm{~km}$. Furthermore, in all cases with $\Delta l \geqq 5 \mathrm{~km}$, the first event is found to rupture in the northwest direction for a distance of about $30 \mathrm{~km}$. The locations of the later events depend on $\Delta l$. Thus, we consider that the spatial distributions of the subevents shown in Figure 7 are not well resolved except for the first event, which is by far larger than the others.

In view of these uncertainties, it is probably reasonable to conclude that the initial event of the Tonghai earthquake ruptured $30 \mathrm{~km}$ in a northwest direction, with a seismic moment of $4.1 \times 10^{26}$ dyne-cm. The later events (here we include subevents 2,3, and 4), which occurred in a time sequence shown in Figure 6, are probably distributed over a much longer segment, with a total moment of $4.6 \times 10^{26}$ dyne-cm. Although the actual spatial extent cannot be determined very well, the spatial spread of the pulses shown in Figure 7 suggests an overall rupture length of about $90 \mathrm{~km}$.

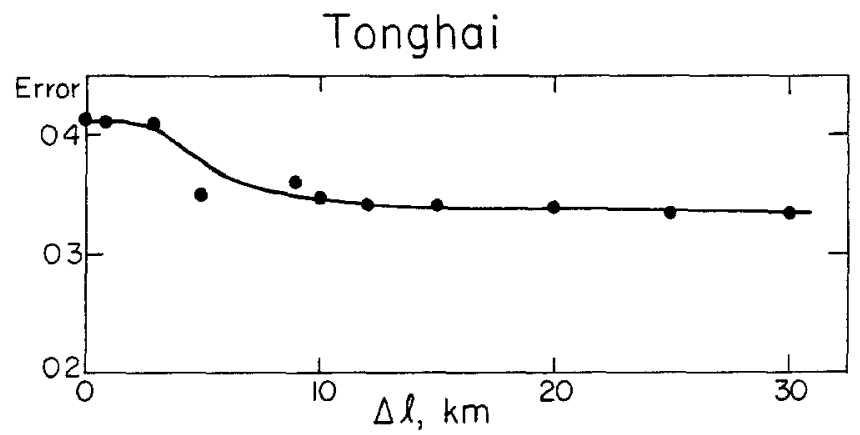

FIG. 8. The error in the match of the synthetic wave to the observed data (Tonghal earthquake) The error becomes significantly small when the separation between the point sources, $\lrcorner l$, is larger than $5 \mathrm{~km}$

In order to estimate the amount of slip from the seismic moment, we assume that the depth extent of the faulting, $w$, is $15 \mathrm{~km}$, which we consider to be a representative value for crustal earthquakes. Then, the slip, $D$, is given by $D=M_{0} / \mu w L$, where $M_{0}$ is the seismic moment, $\mu$ is the rigidity (where $\mu=3 \times 10^{11} \mathrm{dyne} / \mathrm{cm}^{2}$ is used), and $L$ is the rupture length. Using this relation, we obtain $D=3.0 \mathrm{~m}$ for the first event averaged over the $30-\mathrm{km}$ segment northwest of the epicenter. For subevents 2, 3, and 4 combined, we use $L=90 \mathrm{~km}$, and obtain $D=1.1 \mathrm{~m}$ (Table 2).

In Figure 9a, the heavy solid line shows the distribution of slip along the fault estimated above, and the dots indicate the observed field data reported by Zhang and Liu (1978). The two results are generally consistent with each other: both indicate that total displacements were greater northwest of the epicenter than southeast. The larger values estimated here than those of the surface break are consistent with the concept that the extent of faulting at depth was considerably greater than that observed at the surface. The total rupture length observed in the field by Zhang and Liu (1978) was about $48 \mathrm{~km}, 13 \mathrm{~km}$ northwest of the epicenter and $35 \mathrm{~km}$ southeast (Figure 2). On the other hand, the rupture length inferred from the three subevents (Figure 7) is about $90 \mathrm{~km}, 30 \mathrm{~km}$ northwest of the epicenter and $60 \mathrm{~km}$ southeast. These calculated figures agree well with the aftershock distribution (Figure 9b). 
Summarizing these results, the Tonghai earthquake comprised three or four major subevents, the first event rupturing toward the northwest from the epicenter. The total rupture length is $90 \mathrm{~km}$, the total seismic moment $8.7 \times 10^{26}$ dyne-cm, the average displacement $2.1 \mathrm{~m}$, the average stress drop 27 bars, and the duration at least $50 \mathrm{sec}$. These values of seismic moment, displacement, and stress drop are close to those obtained by Wang et al. (1978) using only geodetic data. It is particularly significant that independent seismological, geological, and geodetic

TABLE 2

Parameters of Tonghai Earthquake (4 Jandary 1970, $\left.17 \mathrm{H} 00 \mathrm{M} 39 \mathrm{~S} 24.1^{\circ} \mathrm{N}, 102.5^{\circ} \mathrm{E}, d=15 \mathrm{~km} M_{S}=7.5\right)^{*}$

\begin{tabular}{|c|c|c|c|c|}
\hline $\begin{array}{c}\text { Event } \\
\text { No }\end{array}$ & $\begin{array}{c}M_{0} \\
\left(10^{26} \mathrm{dyne-cm)}\right.\end{array}$ & $\begin{array}{c}T \\
(\mathrm{sec}) \\
\end{array}$ & $\begin{array}{c}L \\
(\mathrm{~km})\end{array}$ & $\begin{array}{c}D \\
(\mathrm{~m})\end{array}$ \\
\hline 1 & 41 & 13 & 30 & 3.0 \\
\hline 2 & 12 & $11]$ & combined & \\
\hline 3 & 1.4 & $11\}$ & 90 & 1.1 \\
\hline 4 & 20 & $15 J$ & & \\
\hline
\end{tabular}

* Total moment $87 \times 10^{26}$ dyne-cm

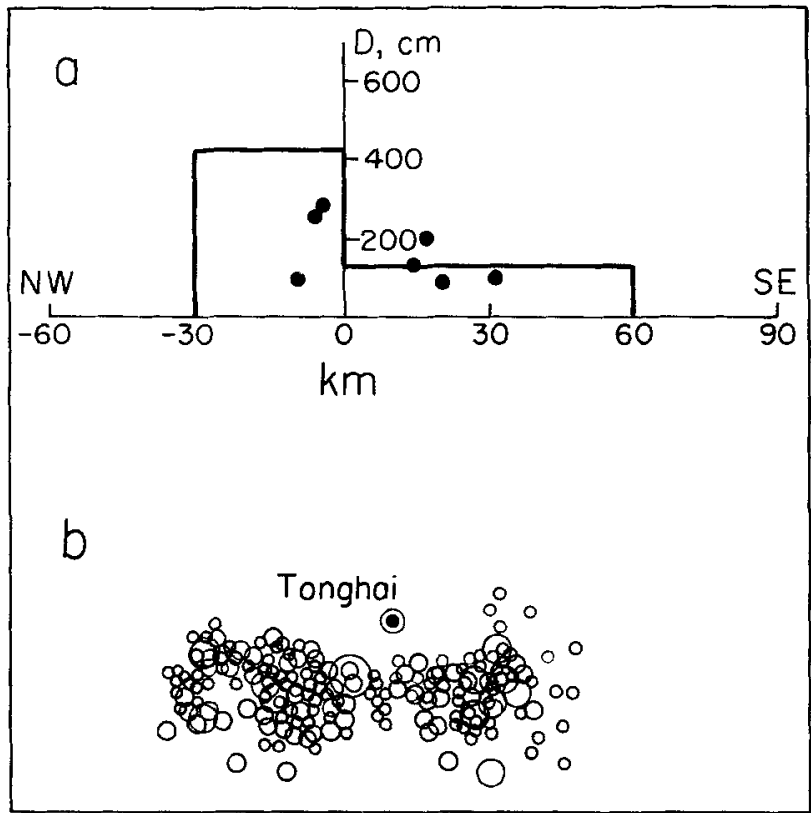

FIG 9 (a) Displacement on Qujang fault as function of distance along fault Heavy solid line represents displacements calculated herein Dots represent field observations of surface fault displacements by Zhang and Liu (1978). (b) Main shock and aftershock locations for the "Tonghai earthquake, from Zhang and Liu (1978).

studies provide self-consistent portrayals of the mechanics of the Tonghai earthquake.

Luhuo earthquake Zhou et al. (1982) analyzed the $P$ waves and surface waves from this event by using a forward trial-and-error method, and they identified three distinct subevents. Here, we attempt to resolve further details.

The focal mechanism of the Luhuo earthquake determined from the $P$-wave firstmotion data is shown in Figure 1c. We take the northwest-striking plane (strike $\phi$ 
$=125^{\circ}, \operatorname{dip} \delta=87^{\circ}$, and the slip angle on this plane $\lambda=0^{\circ}$ ) as the fault plane. We invert the $P$ waveforms from six stations using Kikuchi and Kanamori's (1982) method to obtain the source-time function shown in Figure 10. We use the point source depth of $20 \mathrm{~km}$, rise time $\tau=2 \mathrm{sec}$ and $\Delta l=15 \mathrm{~km}$. The depth is not well constrained. The synthetic waveforms computed for this source-time function match the observed ones reasonably well at all stations except GUA, which is located very close to the $P$-wave radiation-pattern node. A small error in the source mechanism

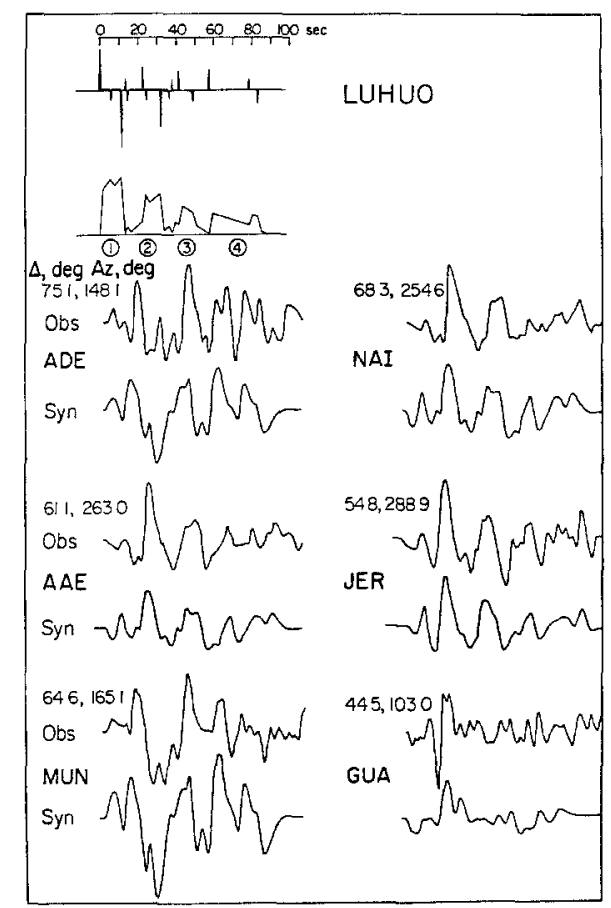

FIG 10 Source-time function for Luhuo earthquake (upper left), together with observed and synthetic $P$ waveforms.

TABLE 3

Parameters of Luhuo EARthquake (6 February 1973 , $\left.10 \mathrm{H} 37 \mathrm{M} 07 \mathrm{~s}, 31.3^{\circ} \mathrm{N}, 100.5^{\circ} \mathrm{E}, d=5 \mathrm{~km}, M_{S}=75\right)^{*}$

\begin{tabular}{|c|c|c|c|c|}
\hline $\begin{array}{c}\text { Event } \\
\text { No }\end{array}$ & $\begin{array}{c}M_{0} \\
\left(10^{26} \text { dyne-cm }\right)\end{array}$ & $\begin{array}{c}T \\
(\mathrm{sec})\end{array}$ & $\begin{array}{c}L \\
(\mathrm{~km})\end{array}$ & $\begin{array}{c}D \\
(\mathrm{~m})\end{array}$ \\
\hline 1 & 6.5 & $14)$ & combined & \\
\hline 2 & 4.9 & $24\}$ & 75 & 3.44 \\
\hline 3 & 3.0 & $19)$ & combined & \\
\hline 4 & 4.1 & $30\}$ & 105 & 15 \\
\hline
\end{tabular}

* Total moment $1.9 \times 10^{27}$ dyne-cm.

of the subevents could have caused this mismatch. The earlier study by Zhou et al. (1982) shows that the third subevent has a slightly different geometry from that of the first two.

Like the Tonghai event, the Luhuo event also comprises four subevents, the parameters for which are given in Table 3 and portrayed in Figure 11. The detailed locations of the subevents are difficult to determine with confidence for the same reason as that discussed for the Tonghai event. The locations of subevents 1 and 2 
indicate that the $75-\mathrm{km}$ segment northwest of the epicenter ruptured in these two events during the first $40 \mathrm{sec}$. The third subevent probably ruptured toward the southeast.

In order to estimate the amount of slip, we assume that: (1) the vertical extent of the fault, $w$, is $15 \mathrm{~km}$; (2) subevents 1 and 2 together (total moment $1.14 \times 10^{27}$ dyne-cm) ruptured the $75-\mathrm{km}$-long segment to the northwest of the epicenter; and (3) the moments of the other events $\left(7.1 \times 10^{26}\right.$ dyne-cm) are distributed over the entire rupture zone defined by the aftershock area $(L=105 \mathrm{~km})$. The distribution of the slip thus estimated is shown in Table 3 and Figure 12a. The asymmetry of the slip distribution about the epicenter is consistent with the asymmetry of surface faulting (Figure 3) (Tang et al., 1976); the largest displacements observed in the field were northwest of the epicenter. Again, the rupture at depth extends to the northwest well beyond the limits of surface rupture and is consistent with the extent

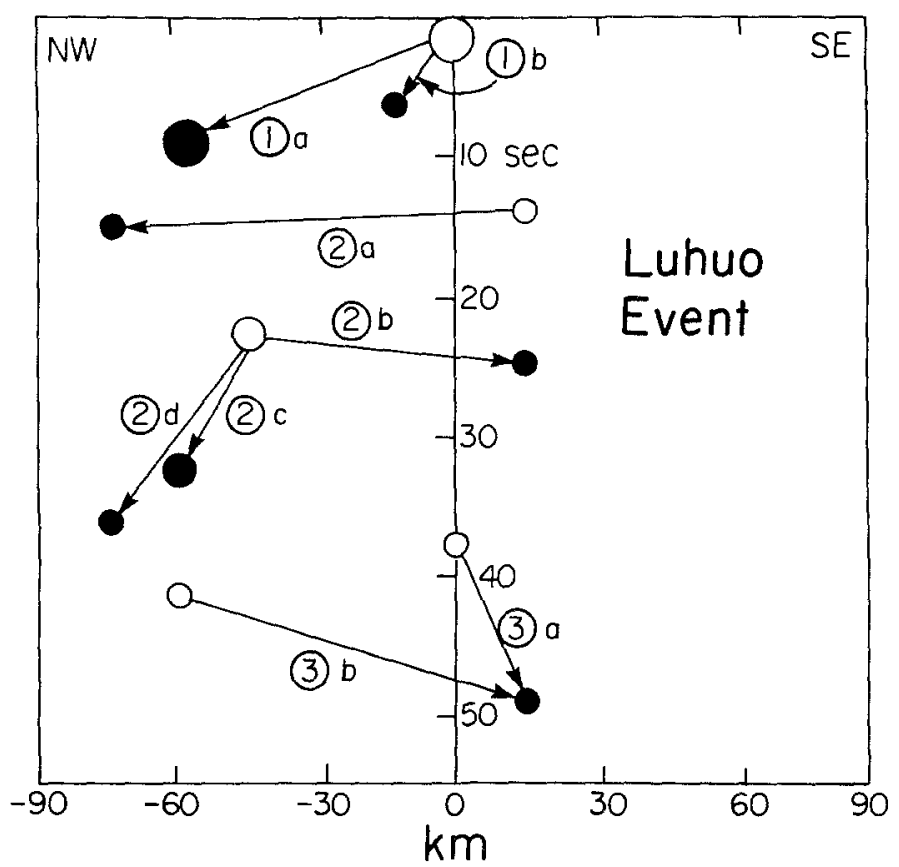

FIG. 11 Time-space distribution of the subevents of the Luhuo earthquake shown in Figure 10

of aftershocks, although one must keep in mind that epicentral control in this area is poor. The two curves resulting from the field observations and the present calculations (Figure 12a) are similar in their amplitudes and asymmetric shapes.

The Luhuo event has a relatively long duration time of $87 \mathrm{sec}$ and a total seismic moment of $1.9 \times 10^{27}$ dyne-cm, which correspond well to the results from surface wave analysis (Zhou et al., 1982). If we distribute this moment over the $105-\mathrm{km}$ long segment, we obtain an average displacement of $4.0 \mathrm{~m}$ and a stress drop of 51 bars. The source-time function shown in Figure 10 differs considerably from that obtained by Zhou et al. (1982), which indicates a relatively small first event. This difference is caused by the difference in the assumed source depth. In the present study, we obtain a best fit with $h=20 \mathrm{~km}$, and the resulting source-time function has a large first event. In Zhou et al. (1982), a source depth of $10 \mathrm{~km}$ is used. Although inversion with a depth of $10 \mathrm{~km}$ results in a less satisfactory fit, we 
consider it acceptable in view of the complexity of the waveform. Thus, whether or not the first event is larger than the later events depends upon the depth, which unfortunately is not known accurately enough to resolve this problem. However, the overall complexity of the source remains the same regardless of the choice of the depth of the point source.

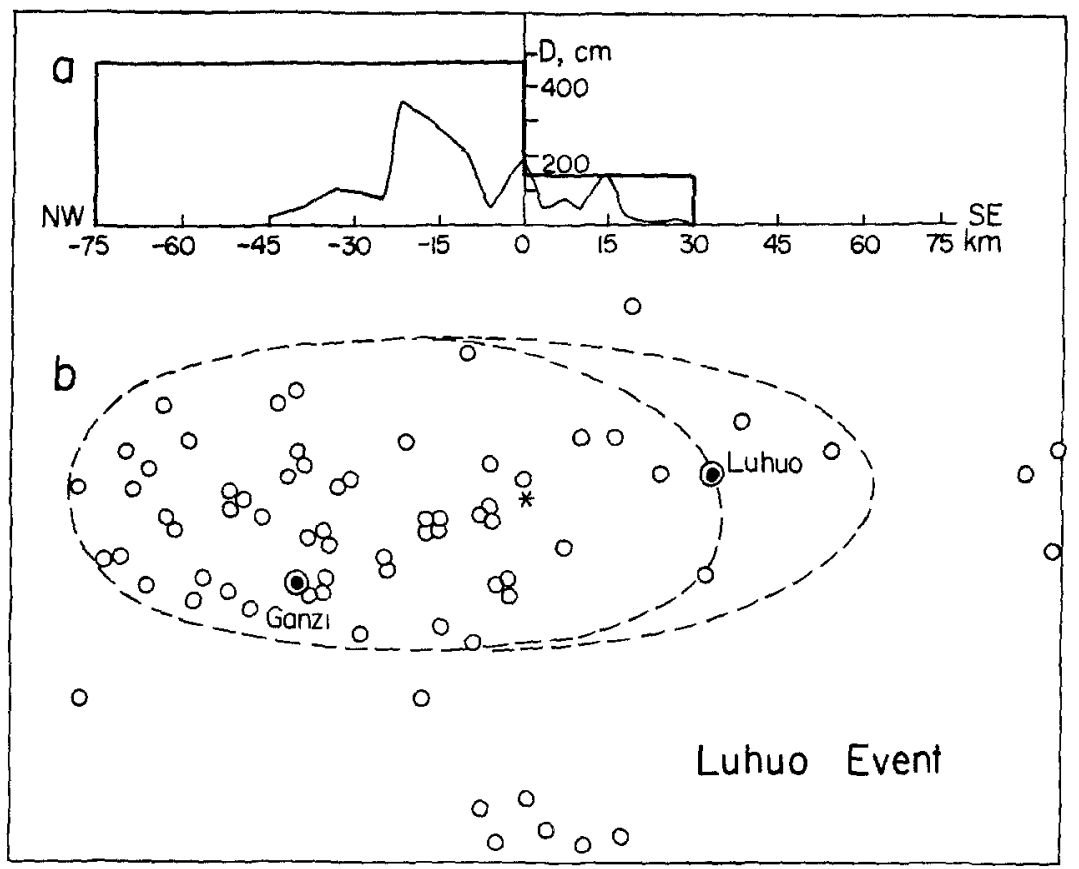

Fic 12 (a) Calculated (heavy line) and observed (thin line) displacements on Xianshuihe fault, with same legend as Figure 9a. Field data from Tang et al (1976) (b) Main shock and aftershock locations of Luhuo earthquake.

\section{Drscussion}

We have shown that the source processes of both the 1970 Tonghai and 1973 Luhuo earthquakes were very complex. Each event included three or four subevents with different moments. Reasonably good consistency has been demonstrated between the calculated rupture patterns and those observed in the field following each of these earthquakes. In our analysis, structural complexities near the source and along the propagation path are ignored, and the overall complexity of the observed waveforms is wholly attributed to the source complexity. It is evident that the structural complexity also contributes to the complexity of the waveform. Furthermore, considerable tradeoff exists between the depth of the point source and the shape of the source-time function. In view of these, the details of the sourcetime functions should not be given too much significance. However, the observed waveforms for the two events studied here are far more complex than those usually observed for smaller events with a simple source-time history, which suggests that the gross features of the source-time functions determined herein represent the real overall source complexity.

The lengths of fault rupture calculated for the two earthquakes are more consistent with the extent of the aftershock areas than the lengths of surface rupture observed in the field on the Xianshuihe and Qujiang faults following the earth- 
quakes. Even these surface ruptures are somewhat longer than those observed for other recent strike-slip events in China of comparable or larger size, such as the 1975 Haicheng, the 1976 Tangshan, and the 1976 Longling earthquakes. It is true, however, that the Tonghai and Luhuo events occurred on seemingly more obvious and throughgoing active faults than did the Haicheng, Tangshan, or Longling events, and this may be an important factor in the nature and extent of surface rupture during large earthquakes.

\section{ACKNOWLEDGMENTS}

This research was supported by US Geological Survey Contract 14-08-0001-21223 and by the Earthquake Research Affilıates of the Calıfornı Institute of Technology.

\section{REFERENCES}

Allen, C. R, A R Gillespıe, Y. Han, K E. Sieh, B. Zhang, and C. Zhu (1982). Quaternary activity of the Red River fault, Yunnan Province, Chına (submitted for publication).

Kan, R., S Zhang, F. Yan, and L. Yu (1977). Present tectonic stress field and its relation to the characterıstıes of recent tectonic actıvity in southwestern China (in Chinese), Acta Geophys. Sinica 20, 96-109.

Heim. A (1934) Earthquake region of Taofu. Bull Geol Soc Am 45, 1035-1050.

Kanamori, H and G. S Stewart (1978) Seismological aspects of the Guatemala earthquake of February 4, 1976, J Geophys Res 83, 3427-3434.

Kıkuchı, M. and H Kanamor (1982) Inversion of complex body waves, Bull Selsm Soc Am 72, 491506

Molnar, P and P. Tapponnier (1975). Cenozoic tectonics of Asia: effects of a continental collision, Sclence 189, 419-426

Slemmons, D B. (1977). Faults and earthquake magnitude, state-of-the-art for assessing earthquake hazard in the Untted States, Rept. 6, Misc. Paper S-73-1, U.S. Army Engineer Waterways Experiment Station, $166 \mathrm{pp}$.

Tang, R -C., D -H Wen, T.-G. Deng. and S -M. Huang (1976) A preliminary study on the characteristics of the ground fractures during the Lu-huo $M=7.9$ earthquake, 1973 and the origin of the earthquake (in Chinese), Acta Geophys. Sinica 19, 17-27.

Wang, C.-Y., C.-N Zhu, and Y.-Q. Liu (1978) Determination of earthquake fault parameters for the Tonghal earthquake from ground deformation data (n Chinese), Acta Geophys Sincca 21, 191-198.

Zhang, S and B. Luu (1978) Seismic characteristıcs of Tonghat earthquake in 1970 (in Chinese), Scientta Geol Sinica 4, 323-335

Zhou, H., H -L. Liu, and H. Kanamorı (1982). Source processes of large earthquakes along the Xıanshuihe fault in southwestern Chnna, Bull Selsm Soc Am 73, 537-551.

SEISMOLOGICAL LABORATORY

CALIFORNIA INSTITUTE OF 'TEChNOLOGY

Pasadena, California 91125

Contribution No. 3789

Manuscript received 15 November 1982 